\title{
Effect of enzymatic transesterification on the melting points of palm stearin-sunflower oil mixtures
}

\begin{abstract}
Transesterification with lipases may be used to convert mixtures of fats to plastic fats, making them more suitable for use in edible products. In our study, 1,3-specific (Aspergillus niger, Mucor javanicus, Rhizomucor miehei, Rhizopus javanicus, and Rhizopus niveus) and nonspecific (Pseudomonas sp. and Candida rugosa) lipases were used to transesterify mixtures of palm stearin and sunflower oil (PS-SO) at a 40:60 ratio in a solvent-free medium. The transesterified mixtures of PS-SO were analyzed for their percentage free fatty acids (FFA), degree and rate of transesterification, solid fat content, slip melting point (SMP), and melting characteristics by differential scanning calorimetry. Results indicated that Pseudomonas sp. lipase produced the highest degree $(77.3 \%)$ and rate $(50.0$ hī 1) of transesterification, followed by R. miehei lipase at $32.7 \%$ and $27.1 \mathrm{hi} 1$, respectively. The highest percentage FFA liberated was also in the reaction mixtures catalyzed by Pseudomonas sp. (2.5\%) lipase and R. miehei (2.4\%). Pseudomonas-catalyzed mixtures produced the biggest drop in SMP $\left(13.5^{\circ} \mathrm{C}\right)$ and showed complete melting at below body temperature. All results indicated conversion of the PS-SO mixtures to a more fluid product. The findings also suggest that the specificity of lipases may not play a significant role in lowering the melting point of the PS-SO mixtures.
\end{abstract}

Keyword: Lipases; Melting properties; Palm stearin; Sunflower oil; Transesterification 